\title{
Evaluating the Value of the Genetic Risk Variants of Haem-Oxygenase-1, Vascular Endothelial Growth Factor and Vascular Endothelial Growth Factor Receptor-2 in Prediction of the Presence of Esophageal Varices in Patients with Liver Cirrhosis
}

\author{
AHMED MOUSTAFA, M.D.*; SHERIF HAMDY, M.D.*; AYMAN RASHAD, M.D.*; \\ WALAA AHMED, M.D.**; AHMED NASHAAT, M.Sc.*** and SAEED M. EL-NAHAAS, M.D.* \\ The Departments of Endemic Medicine \& Hepatology* and Clinical Pathology**, Faculty of Medicine, Cairo University and \\ The Department of Hepatology and Gastroenterology, Ahmed Maher Teaching Hospital***, Cairo, Egypt
}

\begin{abstract}
Background: Current guidelines recommend screening for Esophageal Varices (EV) by Esophagogastroduodenoscopy (EGD) for all cirrhotic patients. The cost and invasive nature of endoscopic screening mean that there is an interest in developing noninvasive predictors for EV that would decrease the number of EGDs performed. The genetic factors that are involved in the development and maintenance of portosystemic collateral circulation have been rarely investigated. Variation at the genes that encode proteins involved in the systemic and splanchnic vasodilation, which include angiotensin-converting enzyme and endothelial/constitutive nitric oxide synthase, have been found to be involved in the EV risk among patients withcirrhosis. In cirrhosis, Vascular Endothelial Growth Factor (VEGF) receptor 2/VEGF and carbon monoxide $(\mathrm{CO})$ activity are significantly increased and are closely correlated with porto-systemic collateral vasodilations. Haem-Oxygenase- 1 (HO-1) is the main ratelimiting enzyme involved in $\mathrm{CO}$ production.
\end{abstract}

Aim of Study: This study aimed at investigating the value of the genetic risk variants of HO-1, VEGF and VEGF Receptor-2 (VEGFR-2) in prediction of the presence of EV in patients with liver cirrhosis.

Patients and Methods: Our study included 300 Egyptian patients with liver cirrhosis, aged 18 years or older, with no history of gastrointestinal bleeding, hepatic schistosomiasis, hepatocellular carcinoma, injection sclerotherapy or band ligation for EV, surgery for portal hypertension or portal or splenic vein thrombosis by ultrasonography. Patients underwent EGD to evaluate the presence and degree of EV, fibroscan for detection of liver stiffness and genetic investigation of HO-1, VEGF and VEGFR-2. Demographic, biochemical and endoscopic data were collected. Patients were divided into Group I (no varices), Group II A (small varices), Group IIB (large varices) and Group III (100 healthy control subjects).

Correspondence to: Dr. Ahmed Moustafa Refaat, E-Mail: Ahmedmoustafarefaat@yahoo.com
Results: All groups were age \& BMI matched, platelet count and serum albumin were significantly lower in group II B compared to groups I \& II A ( $p$-value $<0.001)$, while serum bilirubin level was significantly higher in group II B compared to groups I \& II A ( $p$-value <0.001). TT genotype SNP of HO-1 was associated with the presence of EV, while low grade varices were more detected in patients who carry AT genotype. Other genetic risk variants of VEGF and VEGFR2 were not helpful in the prediction of EV or in the differentiation between small and large varices.

Conclusion: Genetic risk variants of HO-1 genotype are helpful in prediction of EV as well as in differentiation between small and large varices. Combining these genetic variants to other noninvasive parameters will be a more sensitive and specific tool to predict EV in cirrhotic patients; it may help to select patients for endoscopic screening and decrease the number of EGDs. However, further studies will be needed from the economic point of view to determine the applicability of using these noninvasive tools as predictors of varices instead of EGD.

Key Words: Genetic variants - Esophageal varices.

\section{Introduction}

CIRRHOSIS is defined as the histological development of regenerative nodules surrounded by fibrous bands in response to chronic liver injury, which leads to portal hypertension and end-stage liver disease. Recent advances in understanding the natural history and pathophysiology of cirrhosis, and in treatment of its complications, have resulted in improved management, quality of life, and life expectancy of patients [1-7]. EVdevelop as a consequence of increased portal pressure [8]. Increased resistance to portal blood flow is the primary factor in the pathophysiology of portal hypertension, and is mainly determined by the morphological changes 
occurring in chronic liver diseases. This is aggravated by a dynamic component, due to the active reversible contraction of different elements of the porto-hepatic bed. A decreased synthesis of Nitric Oxide (NO) in the intrahepatic circulation is the main determinant of this dynamic component. Another factorcontributing to aggravate the portal hypertension is a significant increase in portal blood flow, caused by arteriolar splanchnic vasodilation and hyperkinetic circulation [9]. Thepresence of EV and the likelihood of their bleeding could potentially be predicted by selected serum and genetic markers, associated with clinicopathological markers like in other populations, as these can vary in different geographic regions [7].

\section{Patients and Methods}

\section{Patient population:}

This is a prospective study that was performed on 300 patients with liver cirrhosis and 100 healthy subjects in the period from February 2016 to December 2017. Patients were recruited from outpatient clinics, Endemic Medicine and Hepatology Department, Gastrointestinal Endoscopy and Liver Unit - Kasr Al-Ainy and Ahmed Maher Teaching Hospital. Diagnosis of liver cirrhosis was based on history, clinical, laboratory and radiological data. After obtaining an informed consent and approval of ethical committee, we enrolled the patients who fulfilled the criteria of liver cirrhosis.

\section{Demographic data and clinical aspects:}

Patients with liver cirrhosis were diagnosed by:

A- Abdominal ultrasonographic criteria; prominent caudate lobe, attenuation of hepatic veins, surface nodularity, coarse texture, signs of portal hypertension (e.g., dilated portal vein, splenomegaly and dilated splenic vein) andascites [7]

B- Sono-elastography: >12.5-15kPa: Cirrhosis [10]

C- Liver biopsy: Grade F4 according to Metavir score (in those who already had a liver biopsy).

We excluded from our study any patientsthat previously had undergone injection sclerotherapy, band ligation or surgery for portal hypertension, those receiving beta blockers, those with hepatocellular carcinoma and portal vein thrombosis, and those with concomitant hepatic schistosomiasis by detection of antibodies to S.mansoni adult worm microsomal antigens.

\section{Our included patients were subjected to:}

A- Full history takingand clinical examination with special emphasis on symptoms and signs of liver cell failure and portal hypertension (e.g. hepatic encephalopathy; jaundice; ascites; splenomegaly; dilated abdominal wall veinsand medication history).

B- Laboratory investigations including Complete Blood Count (CBC), liver functiontests (ALT, AST, serum albumin, bilirubin, coagulation profile and alkaline phosphatase), kidney function testsand alpha fetoprotein assay.

C- Evaluation of Child Pugh score; a clinical score comprising five clinical measures of liver disease; total bilirubin, serum albumin, International Normalized Ratio (INR), ascites and hepatic encephalopathy. Each measure is scored 1-3, with 3 indicating most severe derangement, and Model of end stage liver disease (MELD) scorethat uses the patient's values for serum bilirubin, serum creatinine, and the INR to predict survival.

D- Real time abdominal ultrasonographic evaluation using Toshiba SSA-340A machine with a 3.5 MHZ transducer.

E- EGDusing Olympus GIF 160-Q 165 (EXERA II), to evaluate the presence and degree of varices in addition to any relevant upper GI lesions. Classification of EV was done according to [11]; small EV: $\leq 5 \mathrm{~mm}$ whilelarge $\mathrm{EV}$ : $>5 \mathrm{~mm}$.

F- Liver stiffness measurementusing FibroScan ${ }^{\circledR}$ which is a non-invasive device that assesses the hardnessor stiffnessof the liver via the technique of transient elastography. Theused probe consists of a single-element ultrasound transducer with a central frequency of $3.5 \mathrm{MHz}$ (frequency conventionally used for abdominal ultrasonographic imaging).

G- Molecular genetic analysis including DNA extraction, DNA amplification by Polymerase Chain Reaction (PCR) technique, and genotyping using Restriction Fragment Length Polymorphism (RFLP).

\section{Statistical analysis:}

IBM SPSS statistics (V. 24.0, IBM Corp., USA, 2016) was used for data analysis. Datawere expressed as mean $\pm \mathrm{SD}$ for quantitative parametric measures in addition to both number and percentage for categorized data. Comparison between two independent mean groups for parametric data was done using Student $t$-test. Comparison between more than 2 patient groups for parametric datawas done using Analysis of Variance (ANOVA). The multiple comparisons (Post-hoc test or least significant difference, LSD) were also followed to 
investigate the possible statistical significance between each 2 groups. Chi-square test was used to study the association between each 2 variables or comparison between 2 independent groups as regards the categorized data. Comparison between 2 proportions as regards univariant categorized data was performed. The probability of error at 0.05 was considered significant, while at 0.01 and 0.001 were highly significant. Calculated Relative Risk Assessments (Relative Risk Ratio or RRR) were applied to measure how many times the risk was present among diseased individuals as that among non-diseased ones. They were calculated as absolute figures and as a standard error of estimate (95P). Logisticmulti-regression analysis was used to search for a panel (independent parameters) that can predict the target parameter (dependent variable). By using logistic stepwise multiregression analysis, we can get the most sensitive ones that predict the dependent variable. They can be sorted according to their sensitivity to discriminate according to their $p$-values.

\section{Results}

Our study included three hundred patients with liver cirrhosis who fulfilled the inclusion and exclusion criteria. Patients were divided into two groups according to their EGD findings: Group I: Cirrhotic patients without EV, included 70 patients. Group II: Cirrhotic patients with EV, included 230 patients. Group II was further divided into two subgroups according to the endoscopic grading of $\mathrm{EV}$ on the basis of their size classification and according to (Bloom et al., 2015). Group II A: Included patients with liver cirrhosis and small EV (119 patients). Group II B: Included patients with liver cirrhosis and large EV (111 patients). Group III: One hundred age and sex matched healthy controls. The basic demographic features of the studied patients are shown in (Table 1). The mean age of the patients was 49.7 years. However, the age and BMI showed no statistically significant difference among the studied groups. The percentage of male patients was higher in group I as compared to group II with no statistical significance. The incidence of splenomegalywas significantly higher in group IIB compared to group IIA $\&$ group I ( $36 \%$ vs. $15 \%$ \& $7 \%$ ), respectively ( $p$ value $=0.005)$, however other clinical findings showed no statistical significance among the studied groups.

Table (1): Demographic, clinical and laboratory parameters of the studied patients.

\begin{tabular}{lllll}
\hline & $\begin{array}{c}\text { Group I }=70 \\
\text { Mean } \pm \text { SD }\end{array}$ & $\begin{array}{c}\text { Group II A=119 } \\
\text { Mean } \pm \text { SD }\end{array}$ & $\begin{array}{c}\text { Group II B }=111 \\
\text { Mean } \pm \text { SD }\end{array}$ & $\begin{array}{c}p \text { - } \\
\text { value }\end{array}$ \\
\hline Age (years) & $49.7 \pm 7.38$ & $50.3 \pm 6.04$ & $51.35 \pm 4.98$ & 0.249 \\
Sex (Female/male) & $22(31.4 \%) / 48(68.55 \%)$ & $55(46.2 \%) / 64(53.7 \%)$ & $46(41.4 \%) / 65(58.6 \%)$ & $<0.067$ \\
BMI $\left(\mathrm{kg} / \mathrm{m}^{2}\right)$ & $28.31+3.18$ & $28.65+2.35$ & $27.8+2.67$ & 0.084 \\
Splenomegaly & $5(7 \%)$ & $18(15 \%)$ & $40(36 \%)$ & 0.005 \\
Jaundice $(\mathrm{No} /$ Yes). & $0(0.0 \%)$ & $2(2 \%)$ & $6(6 \%)$ & 0.210 \\
Ascites (No/Yes). & $0(0.0 \%)$ & $1(1 \%)$ & $1(1 \%)$ & 0.777 \\
Hepatic Encephalopathy (No/Yes) & $0(0.0 \%)$ & $0(0.0 \%)$ & $0(0.0 \%)$ & 0.312 \\
MELD Score & $9.8 \pm 3.2$ & $13.5 .5 \pm 2.5$ & $14.8 \pm 1.8$ & $<0.001$ \\
AST/ALT & $1.01 \pm 0.5$ & $1.2 \pm 0.3$ & $1.4 \pm 0.6$ & 0.344 \\
Serum albumin $(\mathrm{g} / \mathrm{dL})$ & $3.1 \pm 0.51$ & $2.95 \pm 0.45$ & $2.49 \pm 0.33$ & $<0.001$ \\
Total Bilirubin $(\mathrm{mg} / \mathrm{dL})$ & $0.92 \pm 0.45$ & $1.42 \pm 0.55$ & $1.95 \pm 0.65$ & $<0.001$ \\
Hb $(\mathrm{g} / \mathrm{dL})$ & $13.91 \pm 1.25$ & $12.37 \pm 1.23$ & $5.09 \pm 4.15$ & 0.000 \\
TLC $\left(\mathrm{X} 10^{3} / \mathrm{mm}^{3}\right)$ & $5.7 \pm 1.87$ & $5.2 \pm 1.67$ & $87.4 \pm 14.59$ & 0.676 \\
Platelets $\left(\mathrm{X} 10^{3} / \mathrm{mm}^{3}\right)$ & $138.6 \pm 25.6$ & $128.08 \pm 11.9$ & $1.37 \pm 0.175$ & $<0.001$ \\
INR & $1.24 \pm 0.216$ & $1.28 \pm 0.157$ & $28.58 \pm 29.95$ & $<0.001$ \\
Alpha fetoprotein $(\mathrm{ng} / \mathrm{ml})$ & $14.84 \pm 13.82$ & $29.85 \pm 32.7$ & 0.008 \\
\hline
\end{tabular}

Our results showed that platelet count and serum albumin were significantly lower in group II B compared to groups I \& II A ( $p$-value $<0.001)$, while serum bilirubin level was significantly higher in group II B compared to groups I \& II A ( $p$-value $<0.001)$. Other laboratory parameters showed no statistically significant difference among the studied groups. As regard the ultrasonographic data as shown in (Table 2), the number of patients with dilated portal vein was significantly higher in group II B compared to groups I \& II A ( $41 \%$ vs. $12 \%$, $24 \%$ ) respectively. On examination by transient elastography, liver stiffness measurement was significantly higher in group II B compared to groups I \& II A (57.43 \pm 11.1 vs. $19.5 \pm 5.29,35.5 \pm$ $10.91)$ respectively, $p$-value $<0.001$. 
Table (2): The ultrasonographic and fibroscanfindings of the studied groups.

\begin{tabular}{|c|c|c|c|c|c|c|c|}
\hline \multirow{2}{*}{ Ultrasound findings } & \multicolumn{2}{|c|}{ Group I } & \multicolumn{2}{|c|}{ Group II A } & \multicolumn{2}{|c|}{ Group II B } & \multirow{2}{*}{$\begin{array}{c}p \text { - } \\
\text { value }\end{array}$} \\
\hline & $\mathrm{N}$ & $\%$ & $\mathrm{~N}$ & $\%$ & $\mathrm{~N}$ & $\%$ & \\
\hline \multicolumn{8}{|l|}{ Portal vein diameter: } \\
\hline Not dilated & 62 & 88 & 90 & 76 & 65 & 59 & \multirow[t]{2}{*}{$<0.001$} \\
\hline Dilated & 8 & 12 & 29 & 24 & 46 & 41 & \\
\hline \multicolumn{8}{|l|}{ Spleen size: } \\
\hline Not enlarged & 32 & 46 & 23 & 19 & 5 & 4 & \multirow{2}{*}{$<0.001$} \\
\hline Enlarged & 38 & 54 & 96 & 81 & 106 & 96 & \\
\hline \multicolumn{8}{|l|}{ Ascites: } \\
\hline $\mathrm{No} / \mathrm{Yes}$ & 1 & 1 & 4 & 3 & 12 & 11 & 0.010 \\
\hline Liver Stiffness "Fibroscan" & \multicolumn{2}{|c|}{$19.5 \pm 5.29$} & \multicolumn{2}{|c|}{$40.5 \pm 11.91$} & \multicolumn{2}{|c|}{$61.43 \pm 13.1$} & $<0.001$ \\
\hline
\end{tabular}

The relationship between liver stiffness value and presence of varices Fig. (1) showed that there is a good reliable cut off for liver stiffness level to predict presence of varices. At a cut off level of $\geq 25.03 \mathrm{Kpa}$, the presence of varices is predicted with sensitivity of $52.9 \%$ and specificity of $52.6 \%$. The $p$-value was 0.380 .
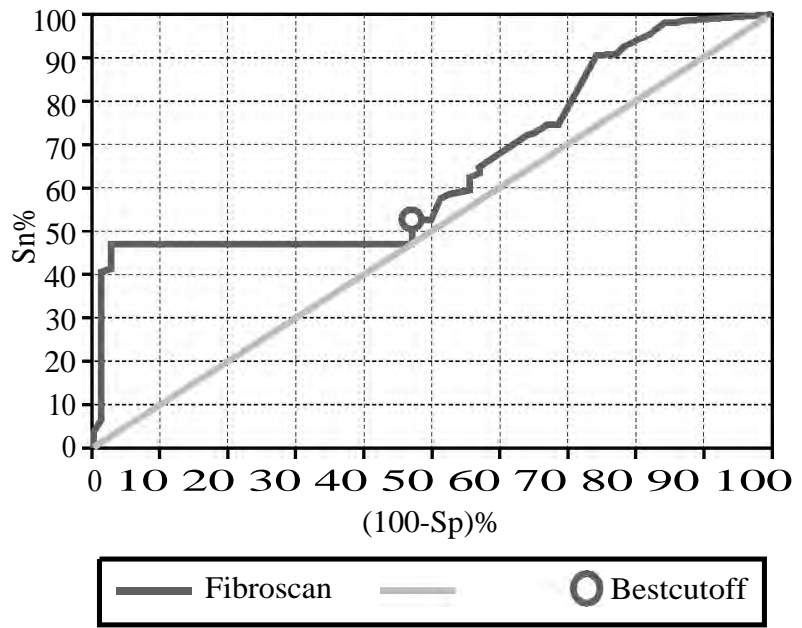

Fig. (1): ROC curve analysis showing the diagnostic performance of fibroscan for discriminating patients with EV from those without.
Regarding the endoscopic findings of the studied groups (Table 3), our data showed that 230 (76.7\%) of cases were presented with EV while $11(3.7 \%)$ with gastric varices. Portal gastropathy was found between $153(51 \%)$ of cases while gastric and duodenal ulcers were found in 11 (3.6\%), 7 (2.4\%) respectively.

Table (3): The endoscopicfindings of the studied groups.

\begin{tabular}{lc}
\hline Parameter & Studied groups $(\mathrm{n}=300)$ Number $(\%)$ \\
\hline EV & $230(76.7 \%)$ \\
Gastric varices & $11(3.7 \%)$ \\
Portal gastropathy & $153(51 \%)$ \\
Gastric ulcers & $11(3.6 \%)$ \\
Duodenal ulcers & $7(2.4 \%)$ \\
\hline
\end{tabular}

As shown in (Table 4), regarding the prevalence of SNPs of HO-1 gene, the AA genotype was the commonest genotype among cases while AT genotype was the commonest among control group. The TT genotype was significantly more frequent in group II in comparison to the control group ( $p$ value $=0.04)$. However, the results showed that the frequency of AT genotypes was significantly higher in group II A compared to group II B ( $p$-value= $0.04)$.

Table (4): Distribution of HO-1 genotypes among the studied groups.

\begin{tabular}{lcccccc}
\hline $\begin{array}{l}\text { HO-1 } \\
\text { Genotypes }\end{array}$ & $\begin{array}{c}\text { Group I }= \\
70\end{array}$ & $\begin{array}{c}\text { Group IIA } \\
119\end{array}$ & $\begin{array}{c}\text { Group IIB } \\
111\end{array}$ & $\begin{array}{c}\text { Group III }= \\
100\end{array}$ & Total & $\begin{array}{c}* p \text { - } \\
\text { value }\end{array}$ \\
\hline AA & $33(22.6 \%)$ & $53(36.3 \%)$ & $60(41.1 \%)$ & $44(44 \%)$ & $190(47.5 \%)$ & $p_{1}=0.04$ \\
AT & $30(24.2 \%)$ & $57(46 \%)$ & $37(29.8 \%)$ & $55(55 \%)$ & $179(44.8 \%)$ & $p_{2}=0.00$ \\
TT & $7(23.3 \%)$ & $9(30 \%)$ & $14(46.7 \%)$ & $1(1 \%)$ & $31(7.8 \%)$ & $p_{3}=0.04$ \\
\hline
\end{tabular}

${ }^{*} p 1=$ Between group II and group III as regard TT genotypes.

$p 2=$ Between group II B and group III as regard TT genotypes.

$p 3=$ Between group II A and group II B as regard AT genotypes.

Regarding the prevalence of SNPs of VEGF gene, no statistically significant difference was found among all the studied groups as shown in (Table 5).
Regarding the prevalence of SNPs of VEGFR2 gene, no statistically significant difference was found among all the studied groups as shown in (Table 6). 
Table (5): Distribution of VEGF genotypes among the studied groups.

\begin{tabular}{llccccc}
\hline VEGF & Group I $=$ & Group IIA $=$ & Group IIB $=$ & $\begin{array}{c}\text { Group III }= \\
100\end{array}$ & Total & $\begin{array}{c}* p- \\
\text { value }\end{array}$ \\
Genotypes & 70 & 119 & 111 & $61 \%(61 \%)$ & $241(60.3 \%)$ & $p 1=0.954$ \\
CC & $46(25.6 \%)$ & $69(38.3 \%)$ & $65(36.1 \%)$ & $61(61 \%)$ & $p_{2}=0.651$ \\
CT & $24(20 \%)$ & $50(41.7 \%)$ & $46(38.3 \%)$ & $39(39 \%)$ & $159(39.8 \%)$ & $p_{3}=0.718$ \\
\hline
\end{tabular}

${ }^{*} p 1$ = Between group II A and group II B as regard CC genotypes.

$p 2=$ Between group II A and group III as regard CT genotypes.

$p_{3}=$ Between group II B and group III as regard CT genotypes.

Table (6): Distribution of VEGFR-2 genotypes among the studied groups.

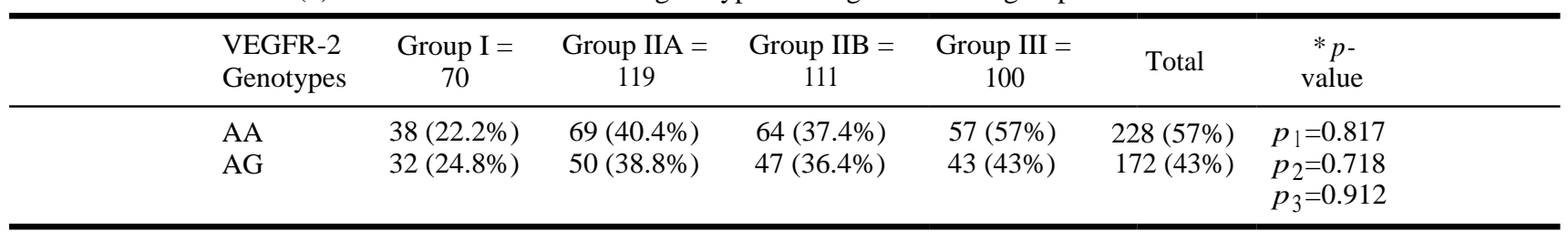

${ }^{*} p 1=$ Between group II A and group II B as regard AA genotypes. $p 2=$ Between group II A and group III as regard AG genotypes. $p 3=$ Between group II B and group III as regard AG genotypes.

Table (7): Multi-regression analysis of predictors of the presence of EV (model 1).

\begin{tabular}{llllllll}
\hline \multirow{2}{*}{ Parameters } & $\begin{array}{c}p- \\
\text { value }\end{array}$ & OR & \multicolumn{2}{c}{$95 \%$ CI for OR } & & Significance & F-Ratio \\
\cline { 5 - 6 } & & & Lower & Upper & & \\
\hline Fibroscan & $<0.001$ & 1.312 & 1.192 & 1.444 & HS & \\
Platelet count & 0.046 & 1000 & 1000 & 1000 & HS & \\
Spleen size & 0.014 & 0.645 & 0.455 & 0.916 & HS & \\
T. bilirubin & $<0.019$ & 0.834 & 0.255 & 0.613 & HS & \multirow{2}{*}{61.052} \\
& $<0.000$ & & & & HS & 61.05 \\
\hline
\end{tabular}

On multi-regression analysis, liver stiffness measurement by fibroscan, platelet count, spleen size and total bilirubin level were the most significant predictors for the presence of EV ( $p$-value $<0.000)$ as shown in (Table 7) (Model 1).
Another model of multi-regression analysis by adding the genetic risk variant of HO-1 (TT) genotype shows no statistical difference as regard the prediction of the presence of varices ( $p$-value $<0.000)$ as shown in (Table 8) (Model 2).

Table (8): Multi-regression analysis of predictors of the presence of EV (Model 2).

\begin{tabular}{llllllll}
\hline \multirow{2}{*}{ Parameters } & \multirow{2}{*}{$\begin{array}{c}p \text { - } \\
\text { value }\end{array}$} & OR & \multicolumn{2}{c}{$95 \%$ CI for OR } & & Significance & F-Ratio \\
\cline { 5 - 6 } & & & Lower & Upper & & \\
\hline Fibroscan & $<0.001$ & 1.112 & 1.078 & 1.148 & HS & \\
Platelet count & 0.042 & 1000 & 1000 & 1000 & HS & \\
Spleen size & 0.014 & 0.645 & 0.455 & 0.916 & HS & \\
T. bilirubin & $<0.019$ & 0.834 & 0.255 & 0.613 & HS & \\
HO-1 (TT) genotype & 0.045 & 0.22 & 0.048 & 1.228 & S & \multirow{2}{*}{ HO } \\
& $<0.000$ & & & & HS & 11.772 \\
\hline
\end{tabular}

\section{Discussion}

Esophageal and gastric varices are a risk for life threatening bleeding. The first step in prevention is to identify the patients at risk of bleeding by endoscopic screening, in order to select them for prophylactic treatment [12]. That's why EGD is recommended for screening for EV for all cir- rhotic patients [13]. However, the cost and invasive nature of endoscopic screening are the reasons behind the interest in developing noninvasive predictors for EV that would decrease the number of EGDs performed [14]. This is why the Baveno $\mathrm{V}$ panel, in order to better stratify patients submitted to endoscopy, recommended identification and validation of alternative noninvasive surrogate 
markers for portal hypertension [15]. Our study aimed to evaluate the role of genetic risk variants of HO-1 and VEGF/VEGFR2 forprediction of the presence of EVin cirrhotic patients with portal hypertension. Meanwhile, we assess whether combining these additional markers with other noninvasive markers could further increase the predictability of EV in cirrhotic patients.

In general, gender differences in incidence, presentation, natural history and outcome exist for common liver disease; it influences the incidence and natural history of many liver diseases. Men usually have more severe liver diseases and the risk of complications and mortality is higher in men than women. In the current study, EV were found more in males than females regardless their grade while there were no statistically significant differences regarding the age and BMI among the three studied groups. However, in some recent studies there was no apparent correlation between gender and development of EV [16]. Moreover, there was association between the presence of EV and age as large EV were significantly associated with older patients, while small EVwere significantly associated with younger patients possibly related to the time availability for the development of portal hypertension and the formation of large varices.

For predicting prognosis of end-stage liver disease, many prognostic models were proposed. Child-Pugh score has been the reference for assessing the prognosis of cirrhosis for about three decades in end-stage liver disease. Despite of several limitations, a large systematic review showed that Child-Pugh score was still robust predictor as many authors concluded [17]. MELDscore emerged as amodernalternative to Child-Pugh score. The MELD score has played an important role to accurately predict the severity of liver disease and effectively assess the risk of mortality. Due to several weak points of MELD score, new modified MELD scores (MELD-Na, delta MELD) have been developed and validated. In our study, the presence ofEV was significantly correlated with increasing severity of liver disease as evidenced by increasing Child score and MELD score. These results match with several authors who showed a strong correlation between the severity of liver disease and the development of varices [18-20]

Splenomegaly is recognized as one of the diagnostic signs of cirrhosis and portal hypertension. In our study, the presence of splenomegaly was the only clinical parameter that was associated with the presence and grading of EV and was confirmed by ultrasonographic examination. Several studies have reported that splenomegaly could be a good predictor of large EV for cirrhotic patients [21-23].

In our study, liver stiffness measurement was significantly higher in patients with EV than those with no varices. It was also significantly higher in patients with large varices than in patients with small varices. Results of the current study are not far from those reported in [24] which recruited 260 patients and concluded that liver stiffness measurement by fibroscan allows the prediction ofEV stage in patients with liver cirrhosis as well as differentiating moderate from severevarices. Thesame parameters were applied in [25] but on a smaller number of 74 patients with and without cirrhosis. They concluded that, transient elastography may help to screen patients who are at high risk of bearing large EV which predict variceal bleeding and therefore, need endoscopic screening.

Concerning the genetic data, our results revealed that the presence of genetic risk variants is helpful in prediction of EV as well as in differentiation between small and large varices. The only previous genetic study about cirrhosis and EV risk was [23] which included all possible etiologies of cirrhosis. It was different from our study by largersample size (951 patients), two years of follow-up for EV bleeding instead of one year in our study. One more thing is that [23] was more concerned with the study of genetic haplotypes while our study was concerned only with the study of genotype SNPs. Our genetic study was characterized by evaluating the role of genetic risk variants in prediction ofvarices as well as in differentiation between small and large varices while [23] was concerned only with the predication of varices. As regard HO-1, our study revealed that the presence of TT genotype is associated with presence of EV while the presence of AT genotype was associated with a low grade of varices rather than high grade. On the other hand, [23] showed that carrying the AS genotype is associated withpresence of EV.

A multivariant analysis in our study showed that the ability to predict EV in cirrhotic patients by combined TT genotype and other noninvasive parameters as fibroscan, platelet count, spleen size and total bilirubin level was greater than these noninvasive parameters alone and this was similar to [23] which showed that carrying both HO-1 AS and VEGF CT risk haplotypes, low platelet count has the ability to predict EV in cirrhotic patients more than low platelet count alone. However, our study revealed that the presence of genetic risk 
variants of VEGF and VEGFR-2 was not helpful in predication of varices or in differentiation between their grades.

Eventually, we recommend that genetic risk variants of HO-1 genotype should be combined with other noninvasive markers for screening of cirrhotic patients for presence of EV as well as for EV grading, thus could limit endoscopic screening and minimizing the complications and cost. Combination of several noninvasive parameters is recommended to replace single assessment to predict portal hypertension, EV \& risk of bleeding with improved sensitivity, specificity and accuracy.

\section{References}

1- DULAK J., DESHANE J., JOZKOWICZ A., et al.: Heme oxygenase-1 and carbon monoxide in vascular pathobiology: Focus on angiogenesis. Circulation, 117: 231-41, 2008.

2- HOLLAND-FISCHER P., GRØNBEÆK H., SANDAHI T.D., et al.: Kupffer cells are activated in cirrhotic portal hypertension and not normalized by TIPS. Gut., 60: 138993, 2011.

3- CHEN Y.H., CHAN L.Y., LIN M.W., et al.: Heme oxygenase-1 gene promoter micro satellite variant is associated with angiographic restenosis after coronary stenting. Eur. Heart J., 25: 39-47, 2004.

4- D'AMICO G., GARCIA-PAGAN J.C., LUCA A., et al.: HVPG reduction and prevention of variceal bleeding in cirrhosis. A systematic review. Gastroenterology, 131: 1624,2006

5- VEAL N., OBERTI F., MOAL F., et al.: Splenic-renal shunt blood flow is an accurate index of collateral circulation in different models of portal hypertension and after pharmacological changes in rats. J. Hepatol., 32: 434-40, 2000.

6- SAUKKONEN K., LAKKISTO P., KAUNISTO M.A., et al.: Heme oxygenase 1 variants and plasma concentrations in critically ill patients. Shock, 34: 558-64, 2010.

7- McGAHAN J.P. and GOLDBERG B.B.: Diagnostic ultrasound. Informa Health Care, 2008.

8- MERLI M., NICOLINI G., ANGELONI S., et al.: Incidence and natural history of small esophageal varices in cirrhotic patients. J. Hepatol., 38: 266-72, 2003.

9- FERNANDEZ M., MEJIAS M., ANGERMAYR B., et al.: Inhibition of VEGF receptor-2 decreases the development of hyperdynamic splanchnic circulation and portalsystemic collateral vessels in portal hypertensive rats. J. Hepatol., 43 (1): 98-103, 2005.

10- CASTERA L., FORNS X. and ALBERTI A.: Non-invasive evaluation of liver fibrosis using transient elastography. J. Hepatol., 48 (5): 835-47, 2008.

11-BLOOM S., KEMP W. and LUBEL J.: Portal hypertension: Pathophysiology, diagnosis and management. Intern. Med. J., 45 (1): 16-26, 2015.
12- BERZIGOTTI A., SEIJO S., REVERTER E., et al.: Assessing portal hypertension in liver diseases. Expert Rev. Gastroenterol. Hepatol., 7 (2): 141-55, 2013.

13- JENSEN D.M.: Endoscopic screening for varices in cirrhosis: Findings, implications, and outcomes. Gastroenterology, 122 (6): 1620-30, 2002.

14- SPIEGEL B.M.R., et al.: The cost-effectiveness and budget impact of competing therapies in hepatic encephalopathya decision analysis. Alimentary Pharmacology \& Therapeutics, 26: 1147-61, 2007.

15- De FRANCHIS R. and BAVENO V. FACULTY: Revising consensus in portal hypertension: report of the Baveno $\mathrm{V}$ consensus workshop on methodology of diagnosis and therapy in portal hypertension. J. Hepatol., 53 (4): 7628, 2010 .

16- AKAHOSHI T., TOMIKAWA M., TSUTSUMI N., et al.: Merits of prophylactic sclerotherapy for esophageal varices concomitant unresectable hepatocellular carcinoma: Prospective randomized study. Dig. Endosc., 26 (2): 172-7, 2014.

17- D'AMICO G., GARCIA-TSAO G. and PAGLIARO L.: Natural history and prognostic indicators of survival in cirrhosis: A systematic review of 118 studies. J. Hepatol. (1): 217-31, 2006.

18- BURTON Jr., LIANGPUNSAKUL S., LAPIDUS J., et al.: Validation of a multivariate model predicting presence and size of varices. J. Clin. Gastroenterol., 41 (6): 609 15, 2007.

19- MOSTAFA H.M., EID K.A., MEGUID M.M., et al.: Comparative study between right liver lobe diameter/ albumin ratio and platelet count/spleen diameter ratio as a non-invasive predictor of esophageal varices in patients with liver cirrhosis. Med. J. Cairo Univ., 81 (1): 875-85, 2013.

20- LISOTTI A., AZZAROLI F., MONTAGNANI M., et al.: Noninvasive diagnosis of portal hypertension and esophageal varices through the identification of liver blood flow markers. Hepatology, 60 (2): 762, 2014.

21- MADHOTRA R., MULCAHY H.E., WILLNER I., et al.: Prediction of esophageal varices in patients with cirrhosis. J. Clin. Gastroenterol., 34 (1): 81-5, 2002.

22- SHARMA S.K. and AGGARWAL R.: Prediction of large esophageal varices in patients with cirrhosis of the liver using clinical, laboratory and imaging parameters. J. Gastroenterol. Hepatol., 22 (11): 1909-15, 2007.

23- YING L., LIN X., XIE Z.L., et al.: Performance of platelet count/spleen diameter ratio for diagnosis of esophageal varices in cirrhosis: A meta-analysis. Dig. Dis. Sci., 57 (6): 1672-81, 2012.

24- LI F., YAN T., SHAO Q., et al.: Clinical study of FibroScan efficiency for diagnosing size of esophageal varices in liver cirrhosis patients. Zhonghua Gan Zang Bing Za Zhi, 22 (8): 600-3, 2014.

25- PÁR G., TROSITS A., PAKODI F., et al.: Transient elastography as a predictor of esophageal varices in patients with liver cirrhosis. Orv. Hetil., 155 (7): 270-6, 2014. 


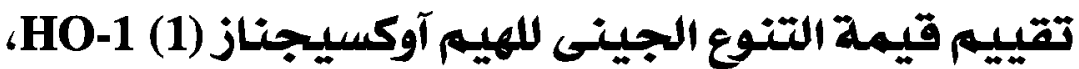

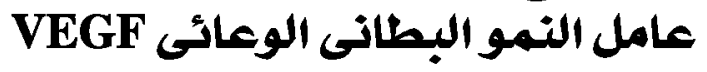

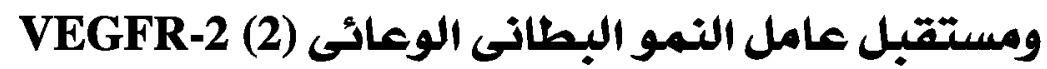

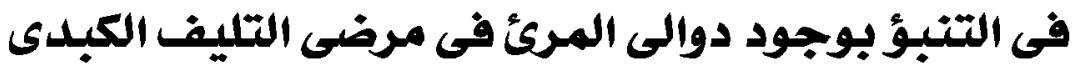

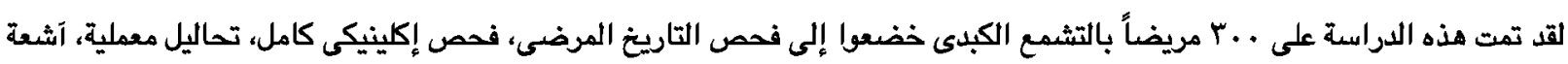

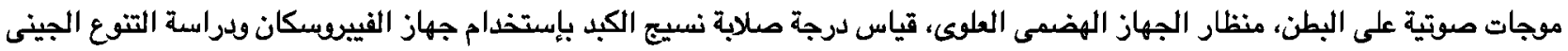
لجينات HO-1, VEGF, VEGFR-2

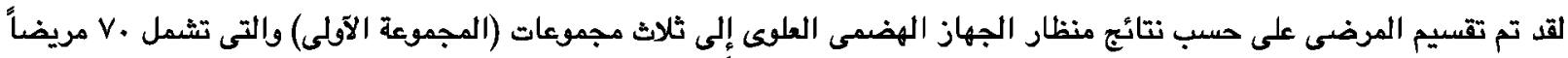

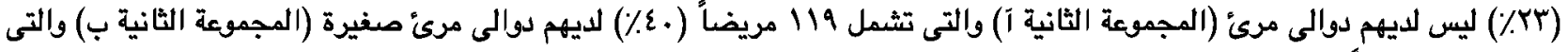

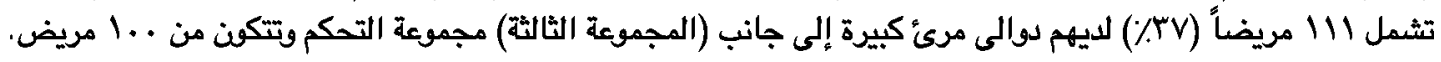

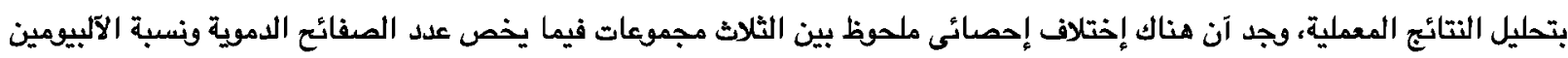
فى الدم ونسبة البيليروبين فى الدم وعلى النقيض، لم يوجد إختلاف ملحوظ فى إنزيمات الكبد وعدد كرات الدم البيضاء بين الثلاث مجموعات. وبقياس درجة صلابة الكبد بإستخدام جهاز الفييروسكان تم إستنتاج آنه يمكن التنبئ بوجود دوالى المرئ.

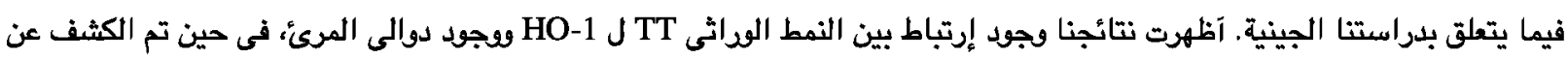

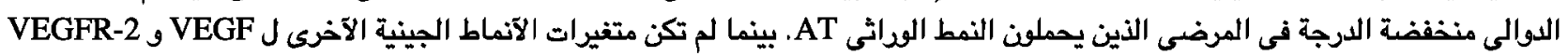
مفيدة فى التبئ بدوالى المرئ آو فى التمييز بين الدوالى النين الصفيرة والكبيرة. 